\title{
Paediatric sports injuries in Hong Kong: a seven year survey
}

\author{
Nicola Maffulli, Rafael C Bundoc, Kai Ming Chan, Jack C Y Cheng
}

\begin{abstract}
Objective-To ascertain the epidemiological characteristics of sports injuries in children in Hong Kong.

Methods-Retrospective review of all cases seen in the Sports Injury Clinic of the Prince of Wales Hospital, Shatin, Hong Kong, in the period May 1984 to December 1990 . The variables studied were age at presentation, gender, side of the body injured, anatomical location of the injury, type and severity of injury, sport played, level (school, recreational, amateur and professional) and frequency of sports participation, length in years of sports practice, and initial management of the injury.

Results-Of the 2293 patients seen, 238
\end{abstract} were youngsters ( $54 \%$ boys) 16 years old or younger. Ball games accounted for the greatest number of injuries, with 37 children taking part in basketball, 28 in soccer, 12 in volleyball, and 31 children taking part in a variety of other ball games. Of the remaining children, the single largest group was practising track and field, with sprinting and middle distance running accounting for 42 injuries, and 28 children were injured while cycling. Most of the injuries $(85 \%)$ were classified as non-serious, but $15 \%$ of children presented with a total of 21 fractures, two joint dislocations, five concussions, and seven torn knee ligaments. Conclusions-Children sports participation in Hong Kong, although not at high level and not as widespread as in the West, accounts for significant morbidity. These injuries should be carefully monitored to ascertain whether they result in any detrimental long term effects.

(Br F Sports Med 1996;30:218-221)

Key terms: sports injuries; children; epidemiology

Department of Orthopaedic Surgery, University of Aberdeen Medical School, Polwarth Building, Foresterhill, Aberdeen AB9 2ZD, United Kingdom N Maffulli, clinical senior lecturer

Correspondence to: N Maffulli.

Accepted for publication 28 November 1995

Competitive sports participation in youngsters has become an established feature of modern society. ${ }^{1}$ The number of children taking part is so high that it has been predicted they might experience negative effects from intensive sports participation at an early age. ${ }^{23}$

The large increase in numbers of participants and in the amount of time spent in training and competing has meant that children now present with injuries that were previously seen almost exclusively in adults. ${ }^{4}$ Low inten- sity training can stimulate bone length, while high intensity training may inhibit it. ${ }^{5}$ Excessive repetitive efforts at an early age may result in serious alterations of the weight bearing joint surfaces. ${ }^{6}$

Three to 11 per cent of school aged children are injured each year when taking part in some form of sports activity, ${ }^{78}$ with boys affected twice as much as girls, ${ }^{9}$ since they engage in higher risk sports and have a higher level of sports activity than girls. Joint laxity is associated with recurrent ligamentous injury, while tightness is strongly correlated with meniscal injuries and ankle, shoulder, and wrist sprains. ${ }^{10}$ The equipment used and the surfaces the sport is played on may have an adjuvant role. ${ }^{10}$

The large differences found between researchers and between sports in the incidence of injuries among sporting youngsters may be for several reasons, such as differences in the definition of injury, the nature of the study (retrospective or prospective), the method of data collection, variability of exposure to the different sports, and the level at which the sport was practised. The studies performed until now have mainly dealt with North American and European children. Although a small percentage of children will be part of ethnic minorities, no studies have focused specifically on Asian children. We report the results of an eight year study on sports injuries in Chinese youngsters presenting in a specialist clinic in Hong Kong.

\section{Methods}

We carried out a retrospective review of all cases seen in the sports injury clinic of the Prince of Wales Hospital in the period May 1984 to December $1990 .^{11}$ In that period, 238 of the 2293 patients seen were youngsters of 16 years or younger. All patients attended the sports injury clinic following referral from another doctor, and all claimed to have been injured during sports participation.

A sports injury reporting form was filled by

each patient or their parent/relative accompanying them. The following variables were collected: age at presentation, gender, side of the body injured, anatomical location of the injury, type and severity of injury, sport played, level (school, recreational, amateur, and professional) and frequency of sports participation, length in years of sports practice, and initial management of the injury. Data on whether injuries occurred in training or competition were not collected. 
Details of sports involved

\begin{tabular}{ll}
\hline Ball games & \\
\hline Basketball & 37 \\
Soccer & 28 \\
Volleyball & 12 \\
Badminton & 9 \\
Handball & 5 \\
Table tennis & 2 \\
Rugby & 2 \\
Softball & 1 \\
Track and field & \\
Sprinting & 15 \\
Middle and long distance running & 10 \\
Long jump & 8 \\
High jump & 5 \\
Other specialties & 18 \\
Water sports & \\
Swimming & 7 \\
Rowing & 1 \\
Martial judo & \\
Judo & 2 \\
Karate & 1 \\
Cycling & 28 \\
Ballet dancing & 10 \\
Gymnastics & 8 \\
Trampolining & 5 \\
Weight training & 2 \\
Roller skating & 3 \\
Others (horse riding, bowling, climbing, etc.) & 17 \\
\hline
\end{tabular}

DATA ANALYSIS

Descriptive statistical analysis was performed. Data were tabulated using contingency tables.

\section{Results}

Of the 238 injured youngsters (average age 13.8 years, range 10 to 16 years), $54 \%$ were boys and $46 \%$ were girls. The age at attendance is given in fig 1 . Details of the sports involved are given in the table. Ball games accounted for the greatest number of injuries, with 37 children taking part in basketball, 28 in soccer, 12 in volleyball, and 31 taking part in a variety of other ball games (fig 2). Of the remaining children, the single largest group practised track and field athletics, with sprinting and middle distance running accounting for 42 injuries. The relatively large number of children injured while cycling (28 cases) is likely to be due to the vicinity to the hospital of a cycling park. When all ball games were grouped together, they accounted for $45 \%$ of the injuries, followed by track and field with $24 \%$. When sports were considered separately, basketball accounted for $15 \%$ of the injuries, and soccer and cycling for $12 \%$ each (fig 2 ).

The upper limb was injured in $13 \%$ of the cases, the spine in $18 \%$, the lower limb in $58 \%$ and the head and neck in $6 \%$ (fig 3). In $5 \%$ of cases, the site of injury was not recorded. When each anatomical region was considered separately, the knee was the region more often injured $(32 \%)$, followed the lumbar spine $(13 \%)$ and the ankle $(12 \%)$.

Injuries to the head were mainly concussions (four cases), and three occurred during basketball games. A boy of 12 suffered from a penetrating injury to the head when hit by a javelin. He required immediate hospital admission, and neurosurgical exploration, followed by a prolonged period of rehabilitation. He recovered, but with residual neurological deficits which prevented his return to sports. In eight cases the face suffered from contusions and lacerations from falls from a bicycle.

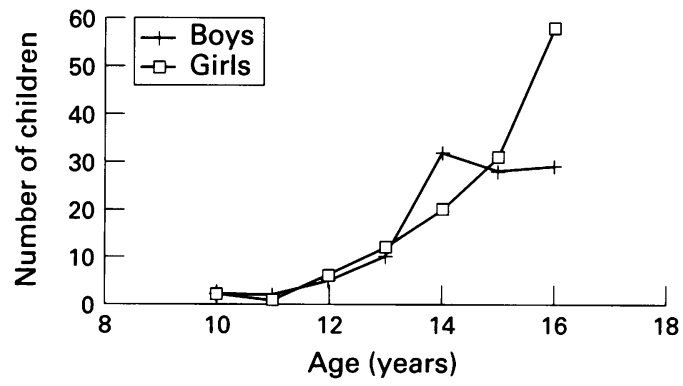

Figure 1 Number of boys and girls seen at the sports injuries clinic of the Prince of Wales Hospital according to
their age.

In the upper extremity, 12 injuries were strains of the shoulder occurring during basketball, volleyball, and swimming. Of the seven fractures of the forearm and wrist, six were due to bicycle falls, when the patient tried to break the fall by landing on the outstretched arm.

Of the 37 soft tissue injuries of the knee, three were a complete tear of the anterior cruciate ligament, two a partial tear of the anterior cruciate ligament, and two a complete rupture of the posterior cruciate ligament, all due to ball games. Arthroscopy was performed in all these cases, confirming the clinical diagnosis. The knee was involved in another serious injury. A boy aged 11 was referred 10 months after a knee injury with an epiphyseal growth disturbance causing genu varum. This was corrected by an osteotomy.

The knee region also accounted for the greatest number of overuse injuries, with a total of eight cases of Osgood-Schlatter lesions, and four of Sinding-Larsen-Johansson lesions. Eight of these youngsters were track and field athletes.

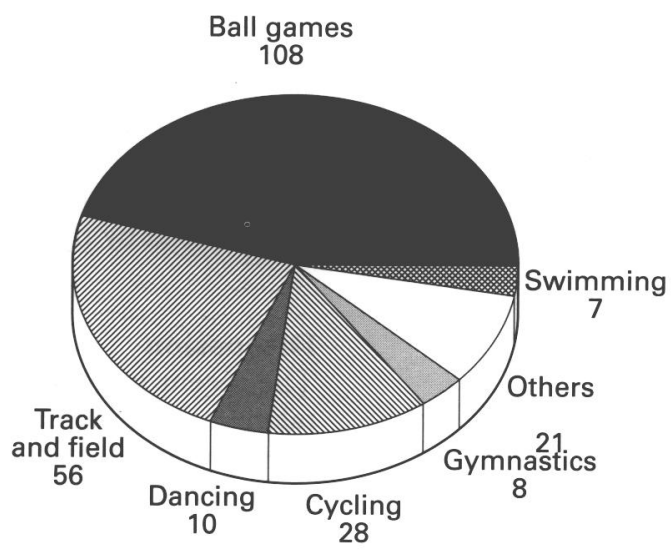

Figure 2 Sports practised.

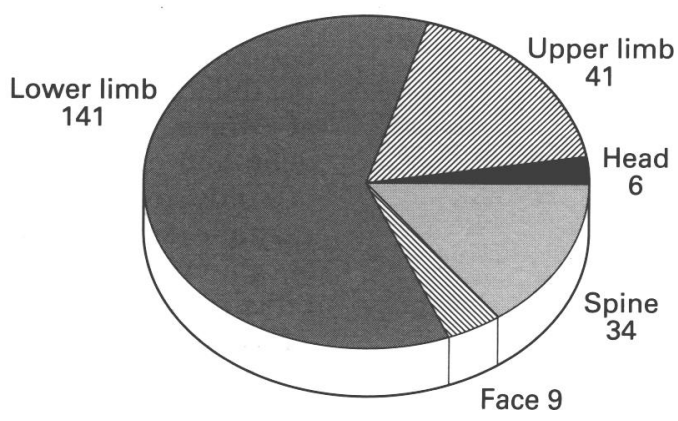

Figure 3 Body part injured. 


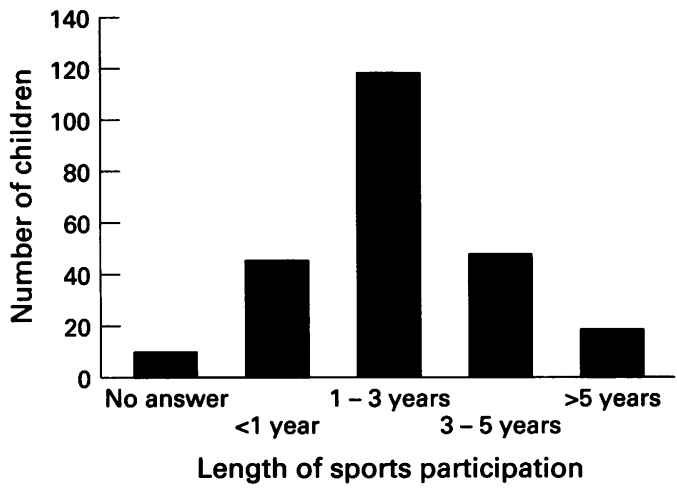

Figure 4 Length of sports participation.

Twenty one youngsters reported acute low back pain following involvement in gymnastics, basketball or volleyball. All responded to conservative management.

Most of the injuries (85\%) were classified as non-serious, and included sprains, contusions, Osgood-Schlatter or Sinding-Larsen-Johansson lesions, and superficial skin abrasions. However, $15 \%$ of children presented with a total of 21 fractures, two joint dislocations, five concussions, and five torn knee ligaments.

The majority of players (64\%) played sports at school level, and a further $20 \%$ were practising recreational sports. The remaining $16 \%$ were amateur or professional players. Most of the patients had been taking part in their sport for more than one year (fig 4 ), and $47 \%$ of the sample practised their sport less than once a week (fig 5).

One hundred and ninety two of the young patients $(81 \%)$ were managed by modified rest, cryotherapy, compression, and elevation. Physiotherapy was given to 123 (51\%) of the patients. Four of the five youngsters with concussion were admitted overnight for observation, while 18 patients were admitted for knee arthroscopy. Ten children underwent closed manipulation of a fracture, and of these three had percutaneous wiring of a fracture of the distal radius. No subsequent morbidity was experienced by these children.

\section{Discussion}

The recent increase in the number of children taking part in organised sports has resulted in a corresponding increase in the number of youngsters' sports injuries, even though the relation is far from clear. ${ }^{12}$ In North America, studies have shown that sports injuries may account for between $11 \%^{13}$ and $27 \%{ }^{14}$ of all childhood accidents. Comparison of results between the various studies is difficult given the different definition of injury used, the level at which the sport is played, the exact definition of the sample studied, and the type of study (retrospective or prospective). ${ }^{15}$ For example, some investigators defined an injury as an event causing the athlete to miss a practice session or a match for at least $48^{16}$ or $72^{17}$ hours.

The extent and severity of injuries reported in this study reflect the level of sports participation of the children who sought medi-

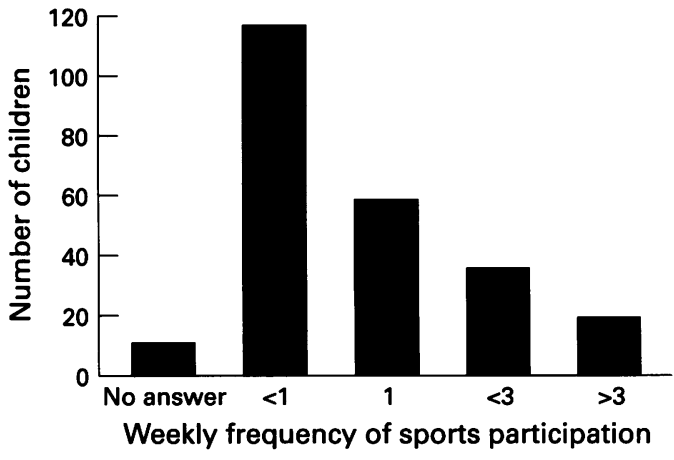

Figure 5 Frequency of sports participation.

cal attention. Although the sports injury clinic is the first and largest tertiary referral specialist clinic in Hong Kong, it is possible that not all sports injuries needing medical attention come to its observation. For example, bone setters are often consulted as first line advisors, and thus the data presented have a nonquantifiable-but surely present-selection bias. The low level of sports participation of the children as a whole is also reflected by the relatively small number of overuse injuries.

One of the problems of dealing with young athletes is that no normative data exist for the various sports. A prospective study of 496 young Danish footballers aged 12 to 18 years, which used a stringent definition of injury, showed an incidence of only 3.7 injuries per 1000 hours of soccer played. ${ }^{18}$ The incidence increased with age, and, in the older children, approximated to the incidence rate of senior players. ${ }^{18} \mathrm{~A}$ direct comparison with our data is not, however, feasible, given the different structure of the sport in Denmark and Hong Kong, and the criteria used in the selection of the sample.

The use of protective clothing may reduce the severity and number of sports injuries. ${ }^{19}$ For example, the use of shin guards was not widespread in youth soccer until 1990 and, by making this compulsory, a number of soft tissue and bone injuries could be avoided.

It is interesting to note the different trend shown during adolescence by boys and girls (fig 1). There is a steady rise in injuries in males with age to the upper limit of 16 , while the girls reach a plateau at 14 . The reasons for this marked difference are unclear, but could be ascribed to either the skeletal maturity normally reached earlier by girls than boys, to a decrease in sports participation in girls at that age, or to a choice of less injurious sports by adolescent girls. At present, however, we are not in a position to produce evidence for or against any of these hypotheses. ${ }^{20}$

The long term effects of the injuries could not be evaluated, given the structure of the study, and future studies in the Asia-Pacific region should focus on the possible deleterious effects of injuries on the musculoskeletal development of young athletes. Also, it is hoped that prospective data collection will be undertaken, and that sporting injuries be classified according to whether they occur during training or competition. 
1 Maffulli N, Pintore E. Intensive training in young athletes. Br F Sports Med 1990;24:237-9.

2 Maffulli $\mathrm{N}$. Intensive training in young athletes. The orthopaedic surgeon's view point. Sports Med 1990;9: 229-43

3 Maffulli N, Helms P. Controversies about intensive training in young athletes. Arch Dis Child 1988;63:1405-7.

4 Kvist M, Kujala UM, Heinonen OJ, Vuori IV, Aho AJ Pajulo $\mathrm{O}$, et al. Sports-related injuries in children. Int $\mathcal{F}$

5 Booth FW, Gould EW. Effects of training and disuse on connective tissue. Exerc Sports Sci Rev 1975;3:83-112. Connective tissue. Exerc Sports Sci Rev 1975;3:83-112. Sowinski J, Golebiewski J, Jozwiak A. Minimum age limits for young

7 Gallagher SS, Finison K, Guyer B, Goodenough S. The incidence of injuries among 87,000 Massa and adolescents: results of the 1980-81 Statewide Childhood Injury Prevention Program Surveillance System. $A m$ f Public Health 1984;8:318-24.

8 Zaricznyi B, Shattuck LJM, Mast TA, Robertson RV, D' Elia G. Sports-related injuries in school-aged children. $A m$ f Sports Med 1980;8:318-24.

9 Beaty $\mathrm{JH}$. Sports related injuries in children and adolescents. Ann Sports Med 1987;3:97- 9.

10 Lysens R, Steverlynck A, van den Auweele Y, Lefevre I Renson L, Claessens A, et al. The predictability of sports Renson L, Claessens A, et al. The

11 Chan KM, Yuan Y, Li CK, Chien P, Tsang G. Sports caus- ing most injuries in Hong Kong. Br $\mathcal{F}$ Sports Med 1993;27: 263-6.

12 Baxter-Jones A, Maffulli N, Helms P. Low injury rates in elite athletes. Arch Dis Child 1993;68:130-2.

13 Tursz A, Crost M. Sports-related injuries in children. A study of their characteristics, frequency, and severity, with comparison to other types of accidental injuries. $\mathrm{Am} F$ Sports Med 1986;14:295-9.

14 Sahlin Y. Sports accidents in childhood. Br 7 Sports Med 1990;24:40-4.

15 Yde J, Nielsen AB. Sports injuries in adolescents' ball games: soccer, handball and basketball. $\mathrm{Br} F$ Sports Med

16 Prager BI, Fitton WL, Cahill BR, Olson GH. High school football injuries: a prospective study and pitfalls of dat collection. Am $\mathcal{f}$ Sports Med 1989;1 7:681-5.

17 Lysens RL, Ostyn MS, Auweela YV, Lefevre J, Vuylsteke M Renson $\mathrm{L}$. The accidentprone and overuse-prone profile of the young athlete. Am $\mathcal{F}$ Sports Med 1989;17:612-9.

18 Schmidt-Olsen $S$, Jorgensen $U$, Kaalund $S$, Sorensen Injuries among young soccer players. Am $f$ Sports Med 1991;19:273-5.

19 Andersen LB, Henckel P. Maximal voluntary isometric strength in Danish adolescents 1619 years of age. Eur $f$ Appl Physiol 1987;56:83-9.

20 Maffulli N, King JB, Helms P. Training in elite young athletes (the training of young athletes (TOYA) study): athletes (the training of young athletes (TOYA) study):
injuries, flexibility and isometric strength. Br $\mathcal{F}$ Sports Med injuries, flexibility 